\title{
Influence of anaerobic fungal administration on growth, rumen fermentation and nutrient digestion in female buffalo calves
}

\author{
J.P. Sehgal ${ }^{1,3}$, D. Jit ${ }^{1}$, A.K. Puniya ${ }^{2}$ and K. Singh ${ }^{2}$ \\ National Dairy Research Institute, \\ ${ }^{1}$ Dairy Cattle Nutrition Division, \\ ${ }^{2}$ Dairy Microbiology Division \\ Karnal -132 001, India
}

(Received 14 February 2008; revised version 4 June 2008; accepted 27 October 2008)

\begin{abstract}
The study was carried out on the effect of administration of anaerobic fungi Neocallimastix sp. GR1 on feed intake, growth, ruminal fermentation, rumen microbial population and nutrient digestion in female Murrah buffalo calves (5 to 8 months of age) for a period of 90 days. In fungus-fed calves ( $250 \mathrm{ml}$ broth $@ \approx 10^{6} \mathrm{tfu} / \mathrm{ml}$; every $4^{\text {th }}$ day), a considerable increase in daily weight gains $(140 \mathrm{~g})$ and better feed efficiency of total mixed ration (3.61\% units) were found when compared with control calves. Besides, the digestibility of dry matter, crude protein, neutral detergent fibre and acid detergent fibre were also higher $(\mathrm{P} \leq 0.05)$ in fungus-fed calves. The digestible energy of total mixed ration in terms of total digestible nutrients was also enhanced. The $\mathrm{pH}$ and $\mathrm{NH}_{3}-\mathrm{N}$ of rumen liquor were found to be lowered, whereas total- $\mathrm{N}$, tricarboxylic acid precipitable-N and total volatile fatty acids and number of zoospore/ml were higher. Hence, the present study suggests that rumen fungi Neocallimastix sp. could be exploited as direct-fed microbials for domesticated ruminants to improve the nutritive value of straw based diets.
\end{abstract}

KEY WORDS: anaerobic fungi, direct-fed microbial, Neocallimastix, digestibility, rumen, buffalo

\section{INTRODUCTION}

High lignin contents of crop residues reduce its digestible energy as lignin encrusts the cell wall and develops ester covalent bonds with celluloses and he-

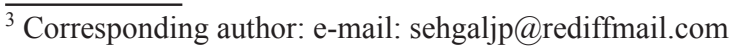


micelluloses, making their digestion difficult for fibrolytic microbes in the rumen. Theodorou et al. (1990) studied the effect of a daily introduction of the rumen fungus Neocallimastix sp. strain R1 into the rumen of calves on feed intake and calves performance, where fungi were found to stimulate forage intake in early-weaned calves, and enhanced liveweight gain. Lee et al. (2000) administered Orpinomyces strain culture, isolated from Korean native goat, to rumen of sheep, and reported increased nutrient digestibility and nitrogen retention. Manikumar et al. (2004) also showed that Orpinomyces sp. isolated from cattle was a promising fungus for higher fibre digestibility of wheat and paddy straws. Dey et al. (2004) reported that anaerobic fungal administration in crossbred calves showed higher productivity in terms of growth rate, feed efficiency and nutrient digestibility. Paul et al. (2004) compared different genera of anaerobic fungi isolated from wild and domestic animals for their degradation and enzymatic activities, and found that Piromyces sp. isolated from blue bull showed increased nutrient digestibility and growth in buffalo calves. Further, Dayananda et al. (2007) studied Piromyces sp. for biodegradation of urea- $\mathrm{NH}_{3}$ treated wheat straw, and found it effective in enhancing digestibility of nutrients and total volatile fatty acids (TVFA) production. Tripathi et al. (2007a) isolated different genera of fungi from wild blue bull and found Piromyces sp. WNG-12 to possess higher hydrolytic activities. He also carried out in vivo trials with same isolate in growing buffalo calves, and found that Piromyces sp. WNG-12 was efficient in improving nutrient digestibility and nutrient utilization. Among domestic ruminants (i.e. buffalo, sheep, goat and cow), goat is considered to be the most efficient in fibre digestion (Elhag, 1976) and fungi mostly help in better fibre digestion, thus it could be assumed that if rumen fungi isolated from goat are administered to other domestic ruminants, and are able to get established in these animals, may enhance the nutrient digestibility and animal productivity with same quantity of feed offered to the animals. Thareja et al. (2006), also isolated anaerobic fungi from sheep and goat, and observed significant in vitro hydrolytic enzyme activities in Neocallimastix $\mathrm{sp}$. GR1 isolated from grazing goat. Hence, the present study was conducted to study the effect of administration of Neocallimastix sp. GR1 on feed intake, growth, ruminal fermentation, rumen microbial population and nutrient digestion in female buffalo calves.

\section{MATERIAL AND METHODS}

\section{Maintenance of culture}

The anaerobic ruminal fungal isolate GR1 (Neocallimastix sp.), originally isolated by Thareja et al. (2006), was procured from Dairy Microbiology Division, 
NDRI, Karnal and was revived using modified Hungate's roll-tube technique as described by Joblin et al. (1981). The roll-tubes were kept in $\mathrm{CO}_{2}$ incubator at $39 \pm 1^{\circ} \mathrm{C}$ and were regularly observed for the appearance of the fungal colonies. The culture purity was checked microscopically based on its morphological characteristics such as monocentric thallus, polyflagellated zoospores, terminal and globular sporangium with stalk at the base, and thick and unsegmented rhizomycellia (Thareja et al., 2006; Dayanand et al., 2007; Tripathi et al., 2007a).

\section{Experimental animals, feeding and housing}

Twelve Murrah female buffalo calves (5 to 8 months of age) with an initial body weight of $122 \mathrm{~kg}$ were selected from the herd of NDRI, Karnal. The animals were divided into two groups of 6 each in a completely randomized design. Animals were fed with a diet consisting of wheat straw, green oats and concentrate mixture. The composition of concentrate mixture and total mixed ration (TMR) on DM basis is given in Table 1. A TMR was offered to meet the

Table 1. Composition of concentrate mixture and total mixed ration (TMR), \%/ton on DM basis

\begin{tabular}{lcc}
\hline Ingredient & Concentrate mixture & TMR \\
\hline Wheat straw & - & 43.5 \\
Oat fodder & - & 10.8 \\
Maize grain & 33.0 & 15.0 \\
Groundnut cake (expeller) & 21.0 & 9.75 \\
Mustard oil seed cake & 12.0 & 5.5 \\
Wheat bran & 20.0 & 9.1 \\
De-oiled rice polish & 11.0 & 5.0 \\
Mineral mixture & 2.0 & 0.9 \\
$\mathrm{NaCl}$ & 1.0 & 0.45 \\
\hline
\end{tabular}

nutritional requirements of the growing calves (Kearl, 1982) for a body weight gain of $500 \mathrm{~g} /$ day. Along with this diet, experimental group of animals were drenched with $250 \mathrm{ml}$ of Neocallimastix sp. GR 1 culture $\left(\approx 10^{6} \mathrm{tfu} / \mathrm{ml}\right)$ on every $4^{\text {th }}$ day per animal, whereas control group was drenched with $250 \mathrm{ml}$ of fungal-free culture media. Throughout the experimental period, the calves were maintained in an open sheeted shed with floor, having arrangement for individual feeding and proper sanitary conditions were maintained. The experimental calves were inspected daily for any disease and mortality. The animals were provided with fresh and clean tap water free choice twice daily at 10.00 and $16.00 \mathrm{~h}$.

The initial liveweights were based on two consecutive daily weighing after 10 days of feeding the experimental diet without any administration of fungal culture 
for adaptation. For growth study, the weight of the individual calf was recorded at a weekly interval for 90 days. The calves were weighed in the morning before they were fed or watered.

\section{Collection and analysis of rumen liquor}

For evaluating the persistence of anaerobic fungi Neocallimastix sp. GR1 in the rumen environment and its effect on rumen fermentation of calves, rumen liquor samples were collected through stomach tube attached with a $100 \mathrm{ml}$ syringe at one end before feeding from all the calves for 3 consecutive days (Lane et al., 1968). One to two drops of saturated mercuric chloride was added to it to stop the microbial activity. Immediately after collection of rumen liquor, the $\mathrm{pH}$ was estimated and samples were kept in refrigerator for further analysis. TVFAs concentration was estimated by the method of Barnett and Reid (1956). Total nitrogen and tricarboxylic acid (TCA) precipitable-N were estimated as per Gerhardt-Kjeldahl's method. Micro-diffusion technique of Conway (1962) was used to estimate $\mathrm{NH}_{3}-\mathrm{N}$. The direct microscopic counts of fungal zoospores were made in rumen liquor samples after appropriately diluting the sample in diluents (Bryant and Burky, 1953).

\section{Digestibility trial}

At the end of experimental feeding, a digestibility trial of seven days duration was conducted in a specially designed stall having a little slope, where the urine was drained out and the faeces were collected manually in buckets. Body weights of the animals were recorded before and after digestibility trial on two consecutive days. A proper record of total feed offered, refusal and faeces voided by each calf was maintained during the trial as per standard procedure.

\section{Chemical and statistical analysis}

Ground samples of concentrate mixture, wheat straw, oats fodder, TMR, feed refusal and those of faeces were analysed for proximate principles, viz., dry matter (DM), crude protein (CP), ether extract (EE), crude fibre (CF) and total ash according to AOAC (1995). Cell wall components of feeds and faeces were estimated by the method of Van Soest et al. (1991).

The statistical analyses were done as per Snedecor and Cochran (1980) using paired T-test for two means. 


\section{RESULTS AND DISCUSSION}

Concentrate mixture with high level of CP, EE and NFE, contributed towards higher proportion of DM compared to roughage source wheat straw and oats green (Table 2). Thus, concentrate mixture supplied higher level of nitrogen

Table 2. Chemical composition of concentrate mixture, wheat straw, green oats and total mixed ration (TMR), \% DM basis

\begin{tabular}{lcccc}
\hline Item & $\begin{array}{c}\text { Concentrate } \\
\text { mixture }\end{array}$ & $\begin{array}{c}\text { Wheat } \\
\text { straw }\end{array}$ & $\begin{array}{c}\text { Oats } \\
\text { green }\end{array}$ & TMR \\
\hline Dry matter & 90.87 & 87.12 & 23.00 & 82.34 \\
Organic matter & 93.16 & 88.71 & 90.36 & 91.87 \\
Crude protein & 20.48 & 3.44 & 8.54 & 11.85 \\
Ether extract & 4.53 & 1.21 & 3.48 & 3.00 \\
Crude fibre & 9.82 & 44.18 & 31.68 & 27.5 \\
N-free extractives & 58.33 & 39.88 & 46.66 & 49.51 \\
Total ash & 6.84 & 11.29 & 9.64 & 9.19 \\
Neutral detergent fibre & 24.87 & 76.92 & 57.78 & 51.74 \\
Acid detergent fibre & 14.34 & 58.21 & 39.42 & 36.61 \\
Acid detergent lignin & 4.42 & 8.76 & 5.18 & 6.46 \\
Hemicellulose & 10.53 & 18.71 & 18.36 & 15.13 \\
Cellulose & 9.92 & 49.45 & 34.24 & 30.15 \\
\hline
\end{tabular}

as well as readily available energy to the animals for rapid growth. Wheat straw was also a potential source of digestible energy; but due to the presence of high contents of ADL, these polysaccharides were not easily available to the ruminants (Sehgal and Punj, 1983). Anaerobic fungi help to make available of this energy by breaking ester bond between lignin and cellulose as well as hemicelluloses by production of aryl enzymes (Borneman et al., 1990, 1992).

Daily gains were higher in fungal culture administered group compared with control, and the differences were statistically significant with nearly similar feed intake (Table 3). There was an improvement in body weight gains of calves fed with TMR administered with fungal culture over control animals. As the growth in the present study pertains only to the accelerating phase of growth, the differences in growth performance in two groups could be attributed to the better utilization of TMR by the animals of fungal administered group, because of the availability of more digestible energy from the breakdown of ligno-cellulose and ligno-hemicellulose bonds of the wheat straw by Neocallimastix sp. GR1. Lee et al. (2000) used a similar technique to enhance the fibre digestion and fermentation in the rumen by increasing the activity of the anaerobic rumen fungi to breakdown the lignocellulolytic bonds of the straw in sheep, and reported that production efficiency 
Table 3. Animal performance, total feed intake, feed efficiency and nutrient utilization

\begin{tabular}{lccc}
\hline Item & Control & Treatment & t-value \\
\hline Initial body weight, kg & $121.55 \pm 4.51$ & $122.63 \pm 6.47$ & $0.18^{\mathrm{NS}}$ \\
Final body weight, kg & $168.37 \pm 6.68$ & $182.02 \pm 6.01$ & $2.70^{*}$ \\
Body weight gain, kg & $46.82 \pm 2.97$ & $59.38 \pm 1.95$ & $3.80^{*}$ \\
Gain/day, g & $520.18 \pm 33.02$ & $659.81 \pm 21.65$ & $3.80^{*}$ \\
Total DMI ${ }^{1}, \mathrm{~kg}$ & $372.93 \pm 15.14$ & $370.46 \pm 17.57$ & $0.23^{\mathrm{NS}}$ \\
DMI/day, kg & $4.14 \pm 0.17$ & $4.12 \pm 0.20$ & $0.23^{\mathrm{NS}}$ \\
Feed efficiency,$\%$ & $12.58 \pm 0.73$ & $16.19 \pm 0.88$ & $3.86^{*}$ \\
Total DCP ${ }^{2}$ intake, kg & $24.76 \pm 0.87$ & $26.59 \pm 1.34$ & $2.01^{\mathrm{NS}}$ \\
DCP intake/day, g & $275.13 \pm 9.68$ & $295.39 \pm 14.86$ & $2.01^{\mathrm{NS}}$ \\
DCP intake/kg gain, g & $538.95 \pm 36.92$ & $490.83 \pm 10.80$ & $1.67^{\mathrm{NS}}$ \\
Total TDN ${ }^{3}$ intake, kg & $196.69 \pm 8.25$ & $221.09 \pm 11.64$ & $2.98^{*}$ \\
TDN intake/day, kg & $2.19 \pm 0.09$ & $2.46 \pm 0.13$ & $2.98^{*}$ \\
TDN intake/kg gain & $4.26 \pm 0.24$ & $4.02 \pm 0.07$ & $1.36^{\mathrm{NS}}$ \\
\hline
\end{tabular}

* - significant $(\mathrm{P} \leq 0.05)$; NS - non significant; \# - kg gain/100 kg DMI; ${ }^{1} \mathrm{DMI}$ - dry matter intake;

${ }^{2} \mathrm{DCP}$ - digestible crude protein; ${ }^{3} \mathrm{TDN}$ - total digestible nutrients

may be increased by 5 to $15 \%$. Dey et al. (2004) observed an improvement of $15.4 \%$ in body weight gains of crossbred cow fed on TMR and administered with fungal culture from cows at a weekly interval. Tripathi et al. (2007b) reported that there was a significant improvement in body weight gains of male calves fed TMR and administered with Piromyces sp. or Orpinomyces sp.

Even though the dry matter intake of the calves was similar in two groups, however, due to the variation in body weight gains, the feed conversion ratio was found to be lower in fungal administered group and the differences were statistically significant. The feed efficiency was significantly higher in fungal administered group than control. Gordon and Phillips (1993) observed the effect of removal of anaerobic fungi from the rumen of sheep on feed intake and in vivo fibre digestion. Dey et al. (2004) also reported that the feed conversion ratio was lower and the feed efficiency was higher in fungal culture administered group than control in crossbred male calves. Tripathi et al. (2007b) also reported the feed conversion ratio to be lower in Piromyces sp. administered and Orpinomyces sp. administered blue bulls than control group.

The digestibility coefficient of DM, OM, CP, CF, NDF, ADF and cellulose content of the TMR increased significantly in experimental group over control. Ether extract digestibility was similar in both the groups (Table 4). Lee et al. (2000, 2004), Dey et al. (2004) and Paul et al. (2004) also reported increased digestibility of fibre fraction and DM following fungi administration.

The digestible crude protein (DCP) value for the fungal administered group increased significantly compared to control. The total digestible nutrients (TDN) 
value were also higher in fungal administered group indicating higher energy availability to the calves due to the higher digestibility of nutrients (Table 4), certainly due to the faster breakdown of fibrous TMR. Though statistically nonsignificant, the protein conversion ratio measured as the DCP intake $/ \mathrm{kg}$ gain

Table 4. Coefficient of apparent digestibility and nutritive value of total mixed ration

\begin{tabular}{lccc}
\hline Item & Control & Treatment & t-value \\
\hline Dry matter & $52.23 \pm 0.87$ & $61.18 \pm 0.73$ & $3.70^{*}$ \\
Organic matter & $53.15 \pm 0.76$ & $62.10 \pm 0.82$ & $3.96^{*}$ \\
Crude protein & $58.70 \pm 1.37$ & $63.33 \pm 1.24$ & $4.54^{* *}$ \\
Ether extract & $85.99 \pm 0.10$ & $85.30 \pm 0.88$ & $0.47^{\mathrm{NS}}$ \\
Crude fibre & $49.99 \pm 1.68$ & $58.08 \pm 1.21$ & $4.11^{* *}$ \\
N-free extractives & $54.14 \pm 2.02$ & $62.63 \pm 1.51$ & $3.08^{*}$ \\
Neutral detergent fibre & $47.20 \pm 1.39$ & $57.73 \pm 1.03$ & $7.53^{* *}$ \\
Acid detergent fibre & $43.43 \pm 2.46$ & $53.15 \pm 2.48$ & $4.46^{* *}$ \\
Cellulose & $57.97 \pm 1.92$ & $68.59 \pm 1.73$ & $6.40^{* *}$ \\
DCP & $6.65 \pm 0.16$ & $7.18 \pm 0.14$ & $3.54^{*}$ \\
TDN & $52.77 \pm 0.94$ & $59.62 \pm 0.63$ & $6.34^{* *}$ \\
\hline
\end{tabular}

* - significant $(\mathrm{P} \leq 0.05)$; ** - significant $(\mathrm{P} \leq 0.01)$; NS - non significant

varied among treatments, and was higher in control than in fungal administered group indicating that less protein was required for a unit of gain. The total TDN intake and TDN intake/day were found to be significantly higher in fungal administered group. The efficiency of energy utilization of control group was numerically low and the intake/kg gain was more compared to fungal administered group. This is result of better utilization of fibrous TMR with Neocallimastix sp. GR1 fungi in experimental group.

The $\mathrm{pH}$ was significantly lower in experimental than in control group. As TMR fed to growing calves had shown a $\mathrm{pH}$ of 7.16 in clarified rumen liquor (CRL), the lower $\mathrm{pH}$ in fungal culture administered group might be due to the enhanced nutrient digestibility and TVFA (Table 5). The availability of more

Table 5. Influence of anaerobic fungi, Neocallimastix sp. GR1, on rumen fermentation pattern

\begin{tabular}{lrrr}
\hline Item & \multicolumn{1}{c}{ Control } & \multicolumn{1}{c}{ Treatment } & \multicolumn{1}{c}{ t-value } \\
\hline $\mathrm{pH}$ & $7.16 \pm 0.04$ & $6.99 \pm 0.04$ & $5.78^{* *}$ \\
Total VFA, $\mathrm{mM} / 100 \mathrm{ml}$ & $10.29 \pm 0.33$ & $13.37 \pm 0.20$ & $6.61^{* *}$ \\
Total nitrogen, $\mathrm{mg} / 100 \mathrm{ml}$ & $77.39 \pm 1.70$ & $105.47 \pm 1.21$ & $5.30^{* *}$ \\
Ammonia nitrogen, $\mathrm{mg} / 100 \mathrm{ml}$ & $13.3 \pm 0.55$ & $8.71 \pm 0.34$ & $6.93^{* *}$ \\
TCA precipitable nitrogen, $\mathrm{mg} / 100 \mathrm{ml}$ & $52.69 \pm 2.11$ & $71.07 \pm 0.81$ & $8.20^{* *}$ \\
Fungal zoospores $/ \mathrm{ml}, \mathrm{x} 10^{5}$ & $1.36 \pm 0.08$ & $3.83 \pm 0.20$ & $13.56^{* *}$ \\
\hline
\end{tabular}

* - significant $(\mathrm{P} \leq 0.05) ; * *$ - significant $(\mathrm{P} \leq 0.01)$ 
TVFAs in the rumen lowered the $\mathrm{pH}$ of the rumen liquor in fungal culture administered diet and the differences were statistically significant. Also, the total$\mathrm{N}$ was significantly higher and $\mathrm{NH}_{3}-\mathrm{N}$ was significantly lower in CRL of fungal administered group than control. Because of this, there was also higher TCA-N in the CRL of experimental group. Also, low $\mathrm{pH}$ observed in this group indicated the availability of more TVFAs after feeding of TMR with rumen anaerobic fungi when low $\mathrm{NH}_{3}-\mathrm{N}$ concentration was observed, even when the total-N concentration remained significantly higher in fungal than in control group. The higher TCA-N production in fungal group might have utilized the maximum $\mathrm{NH}_{3}-\mathrm{N}$ for the microbial protein synthesis due to availability of more TVFAs and more DCP. These results were in close agreement with the values found in the present experiment in the CRL of calves on control diet. The 2.8 fold increase in the zoospore count with the dosing of Neocallimastix sp. GR1 in the rumen of calves was responsible for the breakdown of fibrous material of the wheat straw because these fungi have got higher rate of colonization and hydrolytic activities compared to the normal rumen flora and fauna, and fungi in the calves, due to which there was a significant increase in the digestibility of different nutrients. Elliott et al. (1987) also studied the positive influence of anaerobic fungi on rumen volatile fatty acid concentration in vivo.

\section{CONCLUSIONS}

An increase in digestibility, growth rate and feed efficiency of calves feeding on TMR with administration of Neocallimastix sp. was reported. Hence, rumen fungi can be a promising direct-fed microbial/probiotic in ruminants to improve the nutritive value of straw based diets. However, further research is needed to reach to a definite conclusion before producing an economically viable technology for utilization at farms.

\section{REFERENCES}

AOAC, 1995. Association of Official Analytical Chemists, Official Methods of Analysis. $16^{\text {th }}$ Edition. Arlington, VA

Barnett A.J.G., Reid R.L., 1956. Studies on the production of volatile fatty acids from the grass by rumen liquor in an artificial rumen. J. Agr. Sci. 48, 315-321

Borneman W.S., Hartley R.D., Morrison W.H., Akin D.E., Ljundahl L.G., 1990. Feruloyl and pcoumaroyl esterase from anaerobic fungi in relation to plant cell wall degradation. Appl. Microbiol. Biotechnol. 33, 345-351

Borneman W.S., Ljungdahl L.G., Hartley R.D., Akin D.E., 1992. Purification and partial characterization of two feruloyl esterases from the anaerobic fungus Neocallimastix strain MC2. Appl. Environ. Microbiol. 58, 3762-3766 


\section{EFFECT OF ANAEROBIC FUNGI ON GROWTH OF BUFFALO CALVES}

Bryant M.P., Burkey L.A., 1953. Cultural methods and some characteristics of some of the more numerous groups of bacteria in the bovine rumen. J. Dairy Sci. 36, 205-217

Conway E.J., 1962. Microdiffusion Analysis and Volumetric Error. $5^{\text {th }}$ Edition. Crossby Lockwood and Sons Ltd., London

Dayanand T.L., Nagpal R., Puniya A.K., Sehgal J.P., Singh K., 2007. Biodegradation of urea-NH treated wheat straw using anaerobic rumen fungi. J. Anim. Feed Sci. 16, 484-489

Dey A., Sehgal J.P., Puniya A.K., Singh K., 2004. Influence of anaerobic fungal culture (Orpinomyces sp.) administration on growth rate, ruminal fermentation and nutrient digestion in calves. AsianAustr. J. Anim. Sci. 17, 820-824

Elhag G.A., 1976. A comparative study between goat and sheep efficiency of feed utilization. World Rev. Anim. Prod. 12, 43-48

Elliott R., Ash A.J., Calderon-Cortes J.F., Norton B.W., Bauchop T., 1987. The influence of anaerobic fungi on rumen volatile fatty acid concentration in vivo. J. Agr. Sci. 109, 13-17

Gordon G.L.R., Phillips M.W., 1993. Removal of anaerobic fungi from the rumen of sheep by chemical treatment and the effect on feed consumption and in vivo fibre digestion. Lett. Appl. Microbiol. 17, 220-223

Joblin K.N., 1981. Isolation, enumeration and maintenance of rumen anaerobic fungi in roll tubes. Appl. Environ. Microbiol. 42, 1119-1122

Kearl C.L., 1982. Nutrient Requirement of Ruminants in Developing Countries. International Feedstuff. Utah Agricultural Experiment Station, Utah State University, Logan

Lane G.T., Nellor C.H., Colenbrander V.F., Cummings K.R., Harrington R.B., 1968. Apparatus for obtaining rumino-reticular samples and the effect of sampling locations on $\mathrm{pH}$ and volatile fatty acids. J. Dairy Sci. 51, 114-116

Lee S.S., Choi C.K., Ahn B.H., Moon Y.H., Kim C.H., Ha J.K., 2004 In vitro stimulation of rumen microbial fermentation by a rumen anaerobic fungal culture. Anim. Feed Sci. Tech. 115, 215-226

Lee S.S., Ha J.K., Cheng K.J., 2000. Influence of an anaerobic fungal culture administration on in vivo ruminal fermentation and nutrient digestion. Anim. Feed Sci. Tech. 88, 201-217

Manikumar B., Puniya A.K., Singh K., Sehgal J.P., 2004. In vitro degradation of cell wall and digestibility of cereal straws treated with anaerobic ruminal fungi. Indian J. Exp. Biol. 42, 636-638

Paul S.S., Kamra D.N., Sastry V.R.B., Agarwal N., 2004. Effect of administration of an anaerobic gut fungus isolated from wild blue bull (Boselaphus tragocamelus) to buffaloes (Bubalus bubalis) on in vivo ruminal fermentation and digestion of nutrients. Anim. Feed Sci. Tech. 115, 143-157

Sehgal J.P., Punj M.L., 1983. Utilization of alkali-treated and neutralized wheat straw based rations for growing goat kids. Anim. Feed Sci. Tech. 9, 155-168

Snedecor G.W., Cochran W.G., 1980. Statistical Methods. $7^{\text {th }}$ Edition. The Iowa State University Press, Iowa

Thareja A., Puniya A.K., Goel G., Nagpal R., Sehgal J.P., Singh K., 2006. In vitro degradation of wheat straw by anaerobic fungi from small ruminants. Arch. Anim. Nutr. 60, 412-417

Theodorou M.K., Beever D.E., Haines M.J., Brooks A., 1990. The effect of a fungal probiotic on intake and performance of early-weaned calves. Anim. Prod. 50, 577 (Abstr. 111)

Tripathi V.K., Sehgal J.P., Puniya A.K., Singh K., 2007a. Hydrolytic activities of anaerobic fungi from wild blue bull (Boselaphus tragocamelus). Anaerobe 13, 36-39

Tripathi V.K., Sehgal J.P., Puniya A.K., Singh K., 2007b. Effect of administration of anaerobic fungi isolated from cattle and wild blue bull (Boselaphus tragocamelus) on growth rate and fibre utilization in buffalo calves. Arch. Anim. Nutr. 61, 416-423

Van Soest P.J., Robertson J.B., Lewis B.A., 1991. Methods for dietary fiber neutral detergent and non-starch polysaccharide in relation to animal nutrition. J. Dairy Sci. 74, 3584-3597 